\title{
Continuous Muscle Relaxant Administration for the Management of Severe Tracheomalacia
}

\author{
Takeshi Yano, MD, PhD* \\ Department of Anesthesiology and Intensive Care, Faculty of Medicine, University of Miyazaki, Miyazaki Prefecture, Japan
}

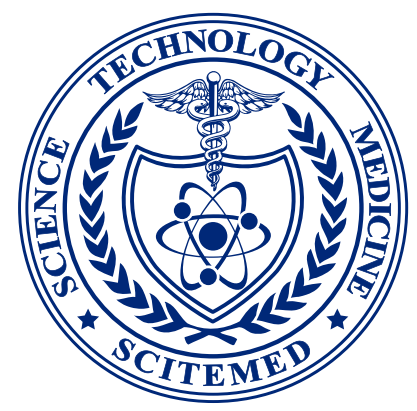

\begin{abstract}
Management of children with severe tracheomalacia is very difficult. Most cases require mechanical ventilation; the mortality rate from severe tracheomalacia is as high as $80 \%$. Crying is often triggered, the respiratory condition gets worse, and eventually, it leads to death. For severe cases, surgical treatment should be considered immediately. Meanwhile, the prevention of fatal attacks by medical treatment is indispensable while waiting for surgery. In this report, a method to manage the patients with severe tracheomalacia using muscle relaxant was discussed. Based on clinical experience, continuous administration of $7 \mu \mathrm{g} / \mathrm{kg} / \mathrm{min}$ of rocuronium was required to prevent life-threatening cyanotic attacks. However, the infusion requirements of rocuronium would show patient-to-patient variability. Further, case reports and evaluation of the effectiveness of muscle relaxants for the treatment of severe tracheomalacia were required.
\end{abstract}

1 racheomalacia is a congenital malformation of the tracheobronchial cartilage that leads to the collapse of the airway and expiratory flow obstruction. Severe cases are rare and usually detected in the neonatal period when children present with acute severe obstructive episodes that can be associated with life-threatening cyanotic attacks [1]. The mortality rate from severe tracheomalacia is as high as $80 \%$ [2]. Up to two-thirds of pediatric patients with this life-threatening symptom die prematurely [2].

Symptoms may be exacerbated by the activities that increase the child's respiratory efforts, including coughing and crying, which can increase intrathoracic pressure until the extraluminal pressure exceeds the intraluminal pressure, and the trachea collapses [2]. To prevent a fatal attack, appropriate sedation and positive pressure ventilation are valid [3]. However, severe obstructive episodes were reported with patients who had been managed by positive pressure ventilation, even during general anesthesia [4].

Tracheostomy or surgical treatments may be useful in tracheomalacia patients who present with life-threatening symptoms [2]. Meanwhile, medical treatments are often required to prevent or remediate a fatal attack, especially in patients waiting for surgical procedures. However, the medical treatment of symptoms associated with severe tracheomalacia has not been established.

Although the clinical efficacy of muscle relaxant for tracheomalacia was unknown, we reported two cases in which continuous muscle relaxant was successfully administered to severe tracheomalacia [5]. That report described the incidences of life-threatening hypoxemia due to tracheomalacia that were repressed by the continuous intravascular administration of rocuronium. After that report, we encountered several similar cases and repeated the continuous intravenous administration of rocuronium. These experiences have led us to convince that rocuronium is an effective drug for the pharmacological treatment of a patient with severe tracheomalacia.

Rocuronium is a widely used non-depolarizing muscle relaxant in clinical anesthesia. Rocuronium-induced neuromuscular blockade can produce optimal intubating and surgical conditions without serious complications, even in pediatric patients [6]. Paralysis of respiratory and airway muscle groups, including the diaphragm, intercostal muscles, and pharyngeal muscles, can be achieved with $0.6 \mathrm{mg} / \mathrm{kg}$ of rocuronium in patients with normal airway anatomies $[7,8]$.

We have decided that the target level of muscle relaxation during mechanical ventilation before tracheostomy should be maintained at a trainof-four (TOF) count of 1 to 2 . The response of the adductor pollicis muscle to electrical stimulation of the ulnar nerve was used for neuromuscular monitoring. The dosage of rocuronium to maintain its muscle relaxation level varies depending on the case. According to our experience, in most cases, hypoxic episodes were extinguished after $7 \mu \mathrm{g} / \mathrm{kg} / \mathrm{min}$ of rocuronium. However, in one case, hypoxic episodes were observed during the administration of $8 \mu \mathrm{g} / \mathrm{kg} / \mathrm{min}$ of rocuronium. In fact, a bolus administration of rocuronium was often required to maintain the level of the TOF count. Woloszczuk-Gebicka et al. reported that the rocuronium infusion rate required for maintaining a stable 90 to $99 \%$ T1 depression in the TOF was $16.7 \mu \mathrm{g} / \mathrm{kg} / \mathrm{min}$ when pediatric patients were anesthetized with fentanyl and nitrous oxide [9]. The infusion requirements of rocuronium show significant patient-to-patient variability and demonstrate an upward trend in children as compared with adults. A much higher infusion rate of rocuronium administration may be required to prevent hypoxic events completely in some cases.

Hypoxic episodes might be prevented by reducing the increase of intrathoracic pressure due to intercostal and abdominal muscle contraction during coughing and crying. Some authors have indicated that the muscle relaxants could have a role in relieving unexpected airway collapse $[3,10,11]$. By the intravenous administration of $1.0 \mathrm{mg}$ of vecuronium, unexpected airway obstruction was relieved during the induction of inhalational anesthesia in a child with a suspected congenital tracheomalacia [3]. In anesthetic management, the induction of general anesthesia with 1 $\mathrm{mg} / \mathrm{kg}$ of succinylcholine could facilitate laryngoscopy and tracheal intubation without airway obstruction in patients with severe tracheomalacia $[10,11]$. Muscle relaxants were also used in infants with tracheomalacia as stabilizing agents during assessments of tracheal collapsibility [12]. Since the stimulation of tracheal smooth muscle in a collapsible trachea can improve airway stability and increase forced expiratory flow, methacholine, a muscarinic cholinergic agonist, is a drug reported to cause improvement in patients with tracheomalacia [13]. Rocuronium has a tendency to release histamine and has also been implicated in bronchoconstriction [14]. Administration of $1 \mathrm{mg} / \mathrm{kg}$ of rocuronium has caused airway narrowing that is mild or not clinically detectable, as reported in clinical research for pediatric patients [14]. Therefore, it is possible that bronchoconstriction related to rocuronium administration has another effect on the improved prevention of hypoxic episodes in tracheomalacia.

Muscle paralysis is also recommended in a stepwise algorithm for unexpectedly difficult pediatric airways based on the protocol of an adult society of difficult airways [15]. Rocuronium can improve facemask ventilation by abolishing airway reflexes and reducing the tone and bulk of muscles [16]. However, it must be noted that the muscle relaxants have 
the potential to worsen the respiratory status of patients with airway obstructions [17]. Caution is required when muscle relaxants are used in patients with airway obstructions when the cause is not primary tracheomalacia but a mechanical obstruction, such as a mediastinal mass or foreign body [18]. Furthermore, continuous administration of muscle relaxants becomes a risk factor for ventilator-associated pneumonia and intensive care-acquired weakness [19]. Quantitative monitoring of neuromuscular function is necessary to avoid the risk of excessive paralysis and its clinical consequences in children.

In conclusion, assessing the effectiveness of muscle relaxants for the treatment of tracheomalacia should be required; however, this might be difficult due to an insufficient number of cases. An extensive retrospective survey and/or various case reports may help us understand how muscle relaxants work.

\section{Article Information}

*Correspondence: Takeshi Yano, MD, PhD

Department of Anesthesiology and Intensive Care, Faculty of Medicine, University of Miyazaki, 5200 Kihara, Kiyotake, Miyazaki 889-1692, Japan.

E-mail: yanotake@med.miyazaki-u.ac.jp

Received: Aug. 01, 2018; Accepted: Sep. 27, 2018; Published: Oct. 15, 2018

DOI: 10.24983/scitemed.acri.2018.00087

Copyright (c) 2018 The Author. This is an open-access article distributed under the terms of the Creative Commons Attribution 4.0 International License (CC-BY).

\section{Funding: None}

\section{Conflict of Interest: None}

\section{Keywords}

Life-threatening cyanotic attacks; muscle relaxants; rocuronium; tracheomalacia.

\section{References}

1. Boogaard R, Huijsmans $\mathrm{SH}$, Pijnenburg MW, Tiddens HA, de Jongste JC, Merkus PJ. Tracheomalacia and bronchomalacia in children: incidence and patient characteristics. Chest 2005;128(5):3391-3397.

2. Carden KA, Boiselle PM, Waltz DA, Ernst A. Tracheomalacia and tracheobronchomalacia in children and adults: an in-depth review. Chest 2005;127(3):984-1005.

3. Okuda $\mathrm{Y}$, Sato H, Kitajima T, Asai T. Airway obstruction during general anaesthesia in a child with congenital tracheomalacia. Eur J Anaesthesiol 2000;17(10):642-644.
4. Asai T, Shingu K. Airway obstruction in a child with asymptomatic tracheobronchomalacia. Can J Anaesth 2001;48(7):684-687.

5. Yano T, Taniguchi M, Tsuneyoshi I. Continuous rocuronium administration for tracheomalacia. J Anesth 2015;29(6):978.

6. Plaud B, Meretoja O, Hofmockel R, et al. Reversal of rocuronium-induced neuromuscular blockade with sugammadex in pediatric and adult surgical patients. Anesthesiology 2009;110(2):284-294.

7. Sachdeva R, Kannan TR, Mendonca C, Patteril M. Evaluation of changes in tidal volume during mask ventilation following administration of neuromuscular blocking drugs. Anaesthesia 2014;69(8):826-831.

8. Hemmerling TM, Schmidt J, Schurr C, Breuer G, Jacobi KE. A comparison between anterior and posterior monitoring of neuromuscular blockade at the diaphragm: both sites can be used interchangeably. Anesth Analg 2002;95(4):940-943.

9. Woloszczuk-Gebicka B, Lapczynski T, Wierzejski W. The influence of halothane, isoflurane and sevoflurane on rocuronium infusion in children. Acta Anaesthesiol Scand 2001;45(1):73-77.

10. Kulkarni K, Deshpande S, Namazi I. Anaesthetic management of a child with multiple congenital anomalies scheduled for cataract extraction. Indian J Anaesth 2009;53(6):683-687.

11. Katoh H, Saitoh S, Takiguchi M, Yamasaki Y, Yamamoto M. A case of tracheomalacia during isoflurane anesthesia. Anesth Analg 1995;80(5):1051-1053.

12. Okazaki J, Isono S, Hasegawa H, Sakai M, Nagase $Y$, Nishino T. Quantitative assessment of tracheal collapsibility in infants with tracheomalacia. Am J Respir Crit Care Med 2004;170(7):780-785.

13. Doshi J, Krawiec ME. Clinical manifestations of airway malacia in young children. J Allergy Clin Immunol 2007;120(6):1276-1278.

14. Yang Cl, Fine GF, Jooste EH, Mutich R, Walczak SA, Motoyama EK. The effect of cisatracurium and rocuronium on lung function in anesthetized children. Anesth Analg 2013;117(6):1393-1400.

15. Weiss $M$, Engelhardt $T$. Proposal for the management of the unexpected difficult pediatric airway. Paediatr Anaesth 2010;20(5):454-464.

16. Patel A. Facemask ventilation before or after neuromuscular blocking drugs: where are we now? Anaesthesia 2014;69(8):811815.

17. Woloszczuk-Gebicka B, Zawadzka-Glos L, Lenarczyk J, Sitkowska BD, Rzewnicka I. Two cases of the "cannot ventilate, cannot intubate" scenario in children in view of recent recommendations. Anaesthesiol Intensive Ther 2014;46(2):88-91.

18. Gautam PL, Kaur M, Singh RJ, Gupta S. Large mediastinal tumor in a neonate: an anesthetic challenge. J Anesth 2012;26(1):124127.

19. Sessler CN. Counterpoint: Should paralytic agents be routinely used in severe ARDS? No. Chest 2013;144:1442-1445. 